\title{
Condições higiênico-sanitárias das cantinas de uma universidade pública em Fortaleza
}

\author{
Adriana Camurça Pontes Siqueira e Ana Karoline de Oliveira Costa ${ }^{2}$
}

A segurança alimentar tem sido amplamente estudada. Uma das formas para atingir alto padrão de segurança do alimento é a implantação das Boas Práticas para Serviços de Alimentação. No campus do Pici da Universidade Federal do Ceará, parcela de estudantes, professores e servidores realizam suas refeições em cantinas. Esses espaços são oferecidos aos permissionários por meio de licitações que não levam em consideração a capacidade de fornecer refeições seguras. A universidade se torna responsável pela segurança dos alimentos fornecidos por estes estabelecimentos e pela saúde dos comensais, quando permite que as refeições sejam comercializadas dentro do campus. Este trabalho avaliou as cantinas existentes no campus dessa universidade, entre março de 2010 a setembro de 2011, por meio da aplicação de checklist com base nas RDCs 216 e 275; capacitou manipuladores de alimentos quanto às Boas Práticas e reavaliou as cantinas após a capacitação. $\mathrm{Na}$ primeira avaliação, todos os estabelecimentos atenderam de 0 a $50 \%$ dos itens do checklist. Após capacitação, 100\% dos estabelecimentos apresentaram melhorias, atendendo de 51 a $75 \%$ dos itens do checklist. A ausência do Manual de Boas Práticas e de fiscalização por parte dos responsáveis desta universidade gera risco de doenças transmitidas pelos alimentos aos estudantes e demais usuários das cantinas.

Palavras-chave: boas práticas, food service, gestão de pessoas, produção de refeições, segurança do alimento.

\section{Hygienic-sanitary conditions of canteens in a public university in Fortaleza.}

Food security has been widely studied. One of the ways to achieve high standards of food safety is the implementation of good practices for food service. In Pici campus of the Federal University in Ceará, students, teachers, and servers have their meals in canteens. These facilities are offered to commercial permit holders through bids, who do not consider the need to provide safe meals. The university not only becomes responsible for offering safe food, which is made in these business establishments, but also for the health of consumers, once these meals are marketed within the Campus. This study evaluated the canteens found in the campus of this university between March 2010 and September 2011. A checklist based on RDC's 216 and 275 was applied, and food handlers were trained regarding good practices. After that, the canteens were re-evaluated. In the first evaluation, all business establishments attended from 0 to $50 \%$ of the items on the checklist. After training 100\% of business establishments, improvements were reported, in which 51 to $75 \%$ of the items of the checklist were fulfilled. The absence of a Guide of Good Practices and supervision from those who are in charge of this university, implicates in high risk of having food poisoning in foods served in these canteens.

Key-words: good practices, food service, managing people, production of meals, food safety.

\footnotetext{
${ }^{1}$ Professora do Curso de Gastronomia do Instituto de Cultura e Arte (ICA) da Universidade Federal do Ceará (UFC). Correspondência: Rua Abdenago, s/n. Campus do Pici, CEP: 60435-001, Fortaleza - CE. E-mail: adriana.nutri@ig.com.br.

${ }^{2}$ Mestranda da Faculdade de Engenharia de Alimentos da UFC.
} 


\section{INTRODUÇÃO}

No Brasil, estima-se um grande aumento e desenvolvimento dos estabelecimentos que produzem alimentos para consumo imediato [1], como fast foods, lanchonetes e cantinas*.

Segundo a Pesquisa de Orçamento Familiar, realizada pelo Instituto Brasileiro de Geografia e Estatística (IBGE), entre maio de 2008 e maio de 2009, a participação da alimentação fora do domićlio nos gastos com alimentação subiu de um quarto $(25,7 \%)$ para um terço $(33,1 \%)^{[2]}$.

Em consonância ao crescimento dos serviços de alimentação a qualidade higiênico-sanitária é um fator de segurança dos alimentos e tem sido amplamente estudada e discutida, uma vez que as doenças transmitidas por alimentos são um dos principais fatores que contribuem para os índices de morbidade e mortalidade nos países da América Latina e do Caribe ${ }^{[1,3,4]}$.

O Comitê da Organização Mundial de Saúde (OMS/FAO) admite que doenças oriundas de alimentos contaminados são, provavelmente, o maior problema de saúde no mundo contemporâneo $\left[{ }^{1}, 3,4\right]$.

No Brasil, as enfermidades provocadas por alimentos contaminados têm sido a causa de vários problemas, além de acarretarem danos à saúde do comensal, são causas de prejuízos às empresas fornecedoras de refeições, comprometendo a qualidade do serviço prestado [5].

Segundo o Ministério da Saúde, através da Secretaria de Vigilância em Saúde (SVS), a "Série histórica de surtos e casos de doenças transmitidas pelos alimentos (DTA), entre 2000 e 2011", mostrou as maiores notificações nos anos de 2001, 2002 e 2005 e, a partir de então, apresentou queda no número de casos, aumentando novamente em 2011. As regiões que apresentaram maiores registros são Sul $(42,1 \%)$ e Sudeste $(37,3 \%)$. As categorias dos produtos mais envolvidos com os surtos nesse período são: alimentos mistos (1.502 casos), ovos e produtos a base de ovos (909 casos), doces e sobremesas (490 casos), água (470 casos) e carne bovina in natura, processados e miúdos
(358 casos). Os agentes etiológicos mais identificados nesses casos são Salmonella spp, S. aureus, E. coli, B. cereus e vírus da hepatite $A$. Os locais que apresentaram maiores números de casos são, respectivamente: residências, restaurantes/padaria, creches e escolas [ ${ }^{[]}$.

Os principais fatores que contribuem para surtos de DTAs, segundo a OMS, que influem na proliferação dos agentes patógenos são: preparação com excessiva antecipação, alimentos deixados à temperatura ambiente, alimentos esfriados em panelas grandes, inadequada conservação a quente, descongelamento inadequado e preparação de quantidades excessivas [1,3,7. Estes fatores podem ser facilmente corrigidos.

Uma das formas para se atingir um alto padrão de segurança do alimento e corrigir problemas relacionados à contaminação é a implantação das Boas Práticas que são compostas por princípios e regras para o correto manuseio de alimentos, abrangendo desde a recepção da matéria-prima até o produto final. O principal objetivo é garantir a integridade do alimento e a saúde do consumidor ${ }^{[8]}$.

A resolução RDC no 216/2004 da Agência Nacional de Vigilância Sanitária (ANVISA) define as Boas Práticas para Serviços de Alimentação como um conjunto de procedimentos que devem ser adotados por serviços de alimentação a fim de garantir a qualidade higiênico-sanitária e a conformidade dos alimentos com a legislação sanitária [?].

Cabe ressaltar que existe diferença entre os termos "segurança alimentar (Food Security)" e "segurança do alimento (food safety)". A segurança alimentar é entendida como a realização do direito de todos ao acesso regular e permanente a alimentos de qualidade, em quantidade suficiente, sem comprometer o acesso a outras necessidades essenciais. Esse conceito tem como base práticas alimentares promotoras de saúde que respeitem a diversidade cultural e que sejam ambiental, cultural, econômica e socialmente sustentáveis [7,10]. O termo "segurança do alimento" está relacionado ao food safety, que pode ser traduzido como "alimento seguro" e se refere ao controle e qualidade higiênico-sanitária do alimento, importante para segurança alimentar [7].

\footnotetext{
* Cantina: lugar onde se fornecem comidas e bebidas aos indivíduos da mesma empresa, fábrica, quartel, escola, etc.
} 
Para Cavalli e Salay, os restaurantes comerciais precisam qualificar a gestão de pessoas, de modo a oferecer condições de segurança dos alimentos à população consumidora. Dessa forma, as autoras sugerem melhorias no processo de recrutamento, seleção e avaliação de desempenho e qualificação dos manipuladores [11].

Manipuladores de alimentos são, de forma geral, todas as pessoas que podem entrar em contato com partes ou com o todo da produção de alimentos, incluindo os que colhem, abatem, armazenam, transportam, processam, ou preparam alimentos, compreendendo, nesse universo, os trabalhadores da indústria e comércio de alimentos, ambulantes e até as donas de casa [12]. A deficiência de formação profissionalizante de manipuladores reflete na higiene pessoal e nas operações de higienização de equipamentos e utensílios [5].

O campus do Pici da Universidade Federal do Ceará (UFC) possui um restaurante universitário (RU), cuja produção de alimentos é terceirizada, ficando a universidade responsável pela fiscalização do serviço prestado, contando com equipe própria e responsável técnico dentro do setor. No entanto, muitos estudantes, professores e servidores optam por realizar suas refeições em cantinas e trailers existentes nos departamentos, por diversas razões: diversidade de serviços - são oferecidas refeições por peso, pratos prontos e lanches do tipo fast food -, fácil acesso; disponibilidade de tempo; necessidade de cadastro dos alunos para recebimento do benefício alimentar no RU; capacidade física limitada do restaurante e variedade das preparações, entre outras.

Os espaços destinados às cantinas no campus do Pici são cedidos aos permissionários através de licitações, no entanto, tal processo não leva em consideração a capacidade de fornecer refeições seguras à comunidade acadêmica usuária desse serviço. Assim, a universidade torna-se responsável pela segurança dos alimentos fornecidos por esses estabelecimentos, a partir do momento em que permite que as refeições sejam comercializadas dentro do campus, tornando também sua responsabilidade a saúde de quem os consome.

Assim, este trabalho buscou avaliar as cantinas existentes no campus do Pici, através de uma lista de verificação (checklist), bem como, capacitar permissionários e manipuladores de alimentos quanto às Boas Práticas e reavaliá-las após a capacitação.

\section{METODOLOGIA}

O presente estudo possui caráter quantitativo, exploratório e descritivo.

Das dez cantinas existentes no campus do Pici da UFC em Fortaleza, oito foram consideradas aptas a fazer parte deste projeto, aceitando participar das avaliações e da capacitação voluntariamente, mediante carta convite. Apenas uma permissionária recusou adesão ao projeto e os responsáveis por outra cantina não foram encontrados.

Para avaliar as cantinas existentes no campus do Pici, foi aplicada uma lista de verificação (checklist) elaborada com base nas resoluções RDCs no 216 de 2004 [9] e no 275 de 2002 [13] da ANVISA (Anexo 1), no período entre março de 2010 e setembro de 2011.

A avaliação dos estabelecimentos foi feita da seguinte forma: inicialmente excluiu-se os itens do checklist que não se aplicavam ao estabelecimento, em seguida fez-se a somatória das respostas positivas (sim) e com esta calculou-se a porcentagem simples do total de itens validos, ou seja, o total das respostas positivas (sim) e negativas (não). Finalmente, os estabelecimentos foram classificados dentro dos seguintes grupos:

- se o estabelecimento atendesse de $0 \%$ a $50 \%$ dos itens do checklist seria classificado no Grupo 3;

- se o estabelecimento atendesse de $51 \%$ a $75 \%$ dos itens do checklist seria classificado no Grupo 2;

- se o estabelecimento atendesse de $76 \%$ a $100 \%$ dos itens do checklist seria classificado no Grupo 1.

De acordo com a classificação acima, os estabelecimentos melhor avaliados se encontram no Grupo 1, seguido por aqueles classificados no Grupo 2 e os estabelecimentos com pior avaliação são classificados no Grupo 3.

O checklist foi aplicado em dois momentos distintos. A primeira aplicação ocorreu antes da capacitação em Boas Práticas com a participação das oito cantinas que aderiram ao projeto e a segunda aplicação ocorreu 3 meses após a capacitação com a participação de sete cantinas e a desistência de um estabelecimento. 
A capacitação foi desenvolvida e aplicada por professores e alunos do curso de gastronomia da UFC, juntamente com uma bolsista do curso de mestrado em engenharia de alimentos. O treinamento teve caráter teórico-prático com duração de 4 horas e ocorreu durante uma manhã no laboratório de preparo de alimentos do curso de gastronomia. O conteúdo teórico da capacitação foi sobre higiene pessoal, higiene dos alimentos, saúde do manipulador, legislação sobre Boas Práticas e Manual de Boas Práticas e o conteúdo prático foi sobre a correta higienização de hortifrutigranjeiros. Vinte manipuladores de alimentos foram convidados a participar da capacitação.

Para a análise dos dados foi utilizado o software Excel@2007.

\section{RESULTADOS E DISCUSSÃO}

\section{Aplicação do primeiro checklist}

Conforme pode ser observado na Tabela 1 a análise dos dados mostra que todos os estabelecimentos avaliados foram classificadas como pertencentes ao Grupo 3 do checklist, cuja característica é o preenchimento de $0 \%$ a $50 \%$ dos itens da lista de verificação, sendo a Cantina 3 (com 19,23\%), o estabelecimento que apresentou menor porcentagem do checklist, ou seja, o pior avaliado; e a Cantina 8 (com $50,53 \%$ ), o estabelecimento que apresentou maior pontuação no checklist, sendo o melhor avaliado.

Tabela 1. Resultados da aplicação do primeiro checklist

\begin{tabular}{c|c|c|c|c|c|c}
\hline $\begin{array}{c}\text { Cantinas } \\
\text { avaliadas }\end{array}$ & $\begin{array}{c}\text { Total da } \\
\text { somatória } \\
\text { de respostas } \\
\text { sim }\end{array}$ & $\begin{array}{c}\text { Total da } \\
\text { somatória de } \\
\text { respostas não }\end{array}$ & $\begin{array}{c}\text { Total da } \\
\text { somatória de } \\
\text { itens válidos }\end{array}$ & $\begin{array}{c}\text { Total da } \\
\text { somatória de } \\
\text { respostas que } \\
\text { não se aplicam }\end{array}$ & $\begin{array}{c}\text { \% de } \\
\text { atendimento } \\
\text { de itens do } \\
\text { checklist }\end{array}$ & $\begin{array}{c}\text { Classificação } \\
\text { das cantinas }\end{array}$ \\
\hline Cantina 1 & 20 & 64 & 84 & 24 & 23,81 & Grupo 3 \\
Cantina 2 & 41 & 50 & 91 & 17 & 45,05 & Grupo 3 \\
Cantina 3 & 15 & 63 & 78 & 30 & 19,23 & Grupo 3 \\
Cantina 4 & 31 & 45 & 76 & 32 & 40,79 & Grupo 3 \\
Cantina 5 & 40 & 52 & 92 & 16 & 43,48 & Grupo 3 \\
Cantina 6 & 17 & 55 & 72 & 36 & 23,61 & Grupo 3 \\
Cantina 7 & 43 & 52 & 95 & 13 & 45,26 & Grupo 3 \\
Cantina 8 & 48 & 47 & 95 & 13 & 50,53 & Grupo 3 \\
\hline
\end{tabular}

Fonte: Elaboração dos autores.

Os maiores problemas encontrados nas cantinas do campus do Pici, apontados pelo checklist, foram também queixas apresentadas pelos próprios permissionários e funcionários, manipuladores de alimentos, dos quais se destacaram:

\subsection{Quanto às instalações}

- a estrutura física das cantinas, como piso, parede, teto, portas e janelas não se encontravam em bom estado de conservação, com desgaste exercido pelo tempo de uso e sem manutenção; apresentando rachaduras, trincas e outros problemas que podem possibilitar a contaminação dos alimentos;

- as edificações e instalações das cantinas não possuíam dimensões físicas que favorecem o fluxo de entrada de alimentos e saída de lixo, ou seja, um fluxo ordenado e sem cruzamentos;

- as cantinas não possuíam telas de proteção nas janelas e portas contra pragas urbanas;

- a área externa às cantinas encontrava-se cercada de focos de insalubridade, tais como, vegetação, animais e lixo.

\subsection{Quanto às instalações sanitárias}

- em algumas cantinas observou-se ausência de sanitários instalados de forma independente da cozinha e em outras, ausência total de banheiros e sanitários para os funcionários. 


\subsection{Quanto aos lavatórios exclusivos para higienização das mãos na área de manipulação de alimentos}

- observou-se a inexistência de pias e lavatórios na quantidade e localização correta.

\subsection{Quanto ao manejo de resíduos}

- o lixo encontrava-se armazenado de forma inadequada. Os recipientes não atendiam a quantidade e capacidade adequadas e não possuíam tampa sem contato manual;

\subsection{Quanto aos manipuladores}

- no que diz respeito à higiene das mãos durante o preparo de alimentos, na troca de serviço e após manipular dinheiro, apesar de todos os manipuladores terem relatado realizar a higiene de mãos com água e sabão, devido à inexistência de pias na quantidade e localização correta, bem como de banheiros para os funcionários, essa afirmação não foi confirmada;

- foram encontrados ainda manipuladores sem o uniforme completo, utilizando adornos e maquiagem, quando mulheres, e barba, no caso dos homens;

- as cantinas não davam para os manipuladores capacitação/treinamentos periódicos em higiene pessoal, em manipulação higiênica dos alimentos e em doenças transmitidas por alimentos.

\subsection{Quanto à documentação e registro}

- as cantinas não possuíam Manual de Boas Práticas e procedimentos operacionais padronizados (POPs), como determina a legislação RDC no 216 de 2004.

\section{Capacitação em Boas Práticas}

Do total de vinte manipuladores de alimentos das cantinas do campus do Pici da UFC, dezoito compareceram à capacitação.

No início da capacitação foram apresentados os resultados do checklist (primeira aplicação), e assim todos os participantes puderam verificar quais os principais problemas encontrados, conforme descrito no item anterior. Em seguida, foi apresentada uma aula teórica sobre higiene pessoal, higiene dos alimentos, saúde do manipulador, legislação sobre Boas Práticas e Manual de Boas Práticas. Na sequência, procedeu-se uma exposição prática sobre a correta higienização de hortifrutigranjeiros.

No final da capacitação, um panfleto contendo as "5 chaves" da preparação segura de alimentos [14] (Figura 1) foi apresentado e distribuído aos participantes com a orientação de ser afixado nas cantinas. Como pode ser observado na Figura 1 as " 5 chaves" são um resumo das "Regras de Ouro" da OMS sobre a preparação inócua dos alimentos, a saber: 1) use água e matérias-primas seguras; 2) mantenha a higiene; 3) separe alimentos crus e cozidos; 4) cozinhe completamente os alimentos; 5) mantenha os alimentos em temperatura segura. 
Figura 1. Panfleto das " 5 chaves" sobre a preparação segura dos alimentos

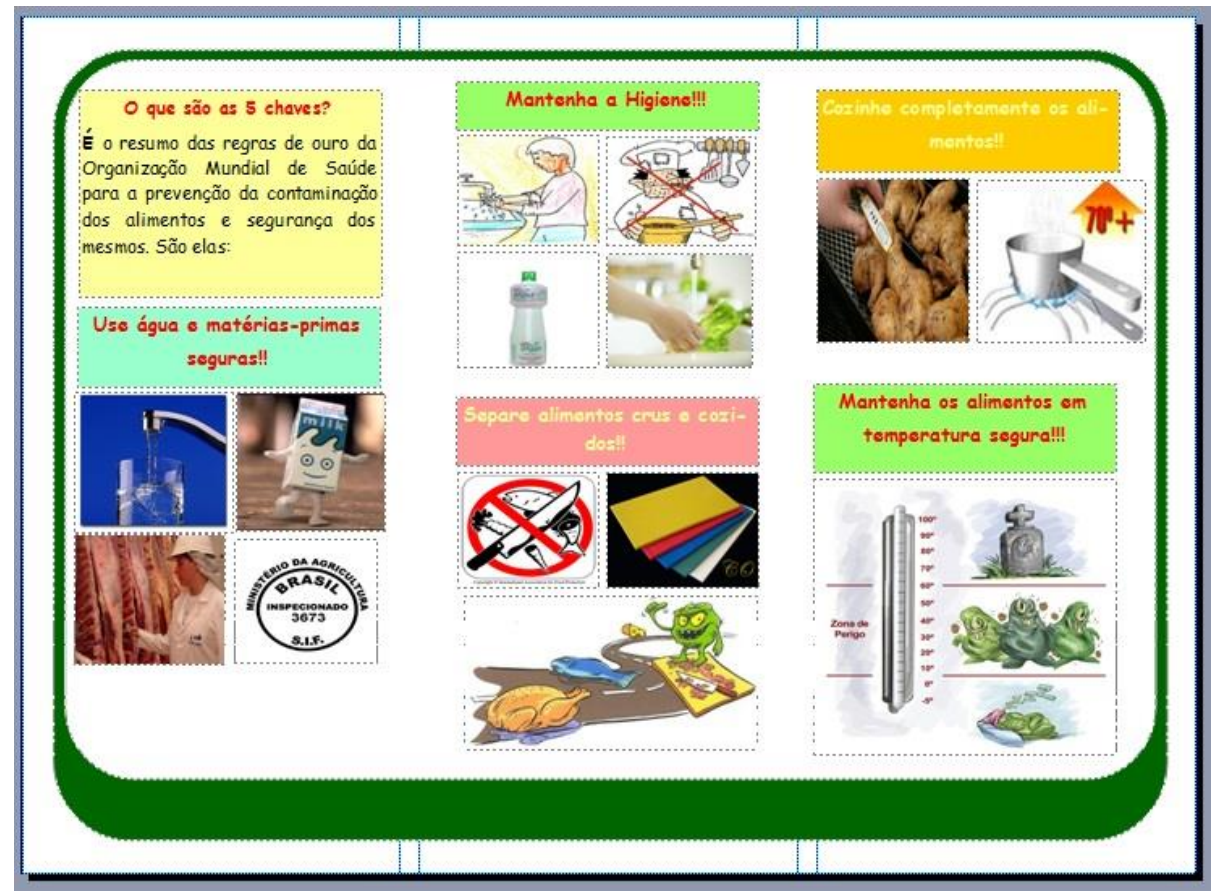

Fonte: WHO [14].

Como forma de estimular a participação, certificados e brindes, como aventais, protetores de cabelo e livros de culinária foram oferecidos juntamente com um lanche aos presentes.

A capacitação em Boas Práticas propiciou a interação entre permissionários e manipuladores de alimentos das diferentes cantinas. Percebeu-se interesse dos manipuladores em participar de novas capacitações.

A maioria dos permissionários da UFC possui a concessão do espaço há mais de 2 anos $(25 \%$ entre 0 e 1 ano; $37,5 \%$ entre 2 e 5 anos; $37,5 \%$ entre 5 e 10 anos). Todos relatam nunca ter fornecido capacitações e treinamentos aos manipuladores sobre higiene dos alimentos e Boas Práticas. Tal situação contribui para as inadequações encontradas nas cantinas avaliadas. Cabe destacar que os procedimentos exigidos pela RDC no 216 de 2004 são de caráter obrigatório para todos os estabelecimentos que produzem, comercializam ou distribuem alimentos.

\section{Aplicação de segundo checklist}

Após 3 meses da capacitação, procedeu-se a uma segunda avaliação dos estabelecimentos através da reaplicação do checklist. Das oito cantinas que participaram da primeira avaliação, sete participaram da segunda avaliação, apenas a Cantina 2, cujo manipulador participou da capacitação, desistiu do projeto e não permitiu a reavaliação do estabelecimento.

A Tabela 2 mostra os resultados da aplicação do segundo checklist.

A análise dos resultados do segundo checklist mostra que as cantinas avaliadas inicialmente no Grupo 3 (com atendimento de $0 \%$ a 50\% dos itens do checklist), conforme apresentado na Tabela 1, passaram a fazer parte do Grupo 2, com atendimento de $51 \%$ a $75 \%$ dos itens avaliados (Tabela 2). 
Tabela 2. Resultados da aplicação do segundo checklist

\begin{tabular}{c|c|c|c|c|c|c}
\hline $\begin{array}{c}\text { Cantinas } \\
\text { avaliadas }\end{array}$ & $\begin{array}{c}\text { Total da } \\
\text { somatória } \\
\text { de respostas } \\
\text { sim }\end{array}$ & $\begin{array}{c}\text { Total da } \\
\text { somatória de } \\
\text { respostas não }\end{array}$ & $\begin{array}{c}\text { Total da } \\
\text { somatória de } \\
\text { itens válidos }\end{array}$ & $\begin{array}{c}\text { Total da } \\
\text { somatória de } \\
\text { respostas que } \\
\text { não se aplicam }\end{array}$ & $\begin{array}{c}\text { \% de } \\
\text { atendimento } \\
\text { de itens do } \\
\text { checklist }\end{array}$ & $\begin{array}{c}\text { Classificação } \\
\text { das cantinas }\end{array}$ \\
\hline Cantina 1 & 45 & 36 & 81 & 27 & 55,55 & Grupo 2 \\
Cantina 3 & 58 & 25 & 83 & 25 & 69,88 & Grupo 2 \\
Cantina 4 & 58 & 24 & 82 & 26 & 70,73 & Grupo 2 \\
Cantina 5 & 46 & 37 & 83 & 25 & 55,42 & Grupo 2 \\
Cantina 6 & 46 & 40 & 86 & 22 & 53,49 & Grupo 2 \\
Cantina 7 & 63 & 25 & 88 & 20 & 71,59 & Grupo 2 \\
Cantina 8 & 48 & 30 & 78 & 30 & 61,54 & Grupo 2 \\
\hline
\end{tabular}

Fonte: Elaboração dos autores.

Como pode ser observado na Tabela 2, a Cantina 6 obteve o pior resultado na segunda avaliação, com atendimento de 53,49\% dos itens do checklist. Contudo apresentou um crescimento de $29,88 \%$, entre a primeira e segunda avaliação, enquanto a Cantina 7 obteve o melhor resultado na segunda avaliação, com atendimento de $71,59 \%$ dos itens do checklist, mas teve um crescimento de $26,33 \%$.

A Cantina 3, que obteve a pior classificação na primeira avaliação (19,23\%), atingiu 69,88\% dos itens do checklist na segunda avaliação e foi a cantina que mais cresceu (50,65\% de crescimento), enquanto a Cantina 8, que conseguiu a melhor classificação durante a primeira avaliação (50,53\%) atingiu na segunda avaliação $61,54 \%$ e foi a cantina que menos cresceu (11,01\% de crescimento).

Após a reavaliação, foram observadas mudanças positivas relativas ao manejo adequado de resíduos, e aos manipuladores, como o uso adequado de uniforme, os cabelos encontravam-se presos e protegidos por redes e toucas, os manipuladores trabalhavam sem adornos e maquiagem, bem como não manipulavam dinheiro, nem praticavam outros atos que pudessem contaminar os alimentos. Outras mudanças importantes ocorreram na melhoria da higiene pessoal, do ambiente, dos utensilios e dos alimentos.

Todas as melhorias fizeram com que as cantinas mudassem seu perfil de Grupo 3 para Grupo 2 do checklist. No entanto, com relação aos aspectos estruturais, os resultados obtidos continuaram os mesmos, visto que entre a primeira e a segunda avaliação não houve reforma na estrutura física das unidades avaliadas. Nesse caso, a responsabilidade por tais reformas de caráter físico-estrutural seria da própria universidade pública.

Terminadas as análises, ficou clara a necessidade de acompanhar tais estabelecimentos, oferecendo parcerias entre a universidade e os permissionários, com o intuito de capacitar manipuladores e oferecer condições estruturais que garantam a segurança dos alimentos comercializados. Para tanto, a instituição de ensino deve ser sensibilizada quanto à responsabilidade de fornecer refeições seguras à comunidade acadêmica.

O desconhecimento de grande parte dos permissionários sobre as legislações que regulam serviços de alimentação em cantinas, principalmente a RDC no 216 de 2004 [9], que regulamenta as Boas Práticas, também contribuíram para a situação encontrada.

É importante destacar que este não é um caso isolado e que tal situação se repete em outras universidades brasileiras. Em estudo similar realizado no campus da Universidade Federal da Bahia (UFBA) [15], utilizando um formulário semiestruturado e previamente testado, elaborado de acordo com recomendações e normas contidas no Manual da Associação Brasileira das Empresas de Refeições Coletivas (ABERC) e na portaria no 6/99, de 10 de março de 1999, do Centro de Vigilância Sanitária do Estado de São Paulo, constatou-se que as cantinas existentes no local não atenderam aos requisitos de higiene dos alimentos, necessários para a produção de alimentos seguros, indicando riscos para os consumidores. 
Em outra universidade, no Rio Grande do Sul, avaliou-se o nível de adequação em Boas Práticas de uma cantina universitária utilizando a lista de verificação da resolução RDC no 275 de 21 de outubro de 2002, por meio da qual foram diagnosticadas as condições higiênico-sanitárias; em seguida, elaborou-se um plano de ação para corrigir as inadequações. $\mathrm{O}$ estudo ocorreu durante um período de 9 meses no ano de 2004. A lista de verificação foi aplicada em dois momentos, antes e após o término das atividades, que resultaram em 3 capacitações com duração de uma hora cada. Os manipuladores foram treinados por meio de entrega de cartilhas e cartazes educativos e explicativos, que foram distribuídos pelas áreas da cantina. Como resultado, houve um crescimento significativo e visível na qualidade e segurança do alimento servido, tendo sido comprovado com a segunda aplicação da lista de verificação, uma melhoria de $60,15 \%$ de atendimento à legislação para $80,45 \%$, passando de um estabelecimento classificado no Grupo 2 para o Grupo 1, ou seja, que atinge de 76\% a $100 \%$ a legislação ${ }^{[16] .}$

No Paraná, outro estudo semelhante realizado em uma universidade federal, durante a tentativa de implantar as Boas Práticas na cantina existente no campus, foi feita uma avaliação em toda a empresa, seguindo o checklist da resolução RDC no 275, de 21 de outubro de 2002. Em seguida, foi elaborado um relatório com as não conformidades encontradas e um plano de ação para as correções necessárias. Para a avaliação higiênico-sanitária foi utilizada uma ficha de inspeção baseada na RDC no 216 de 2004, contendo 61 itens, dividida em 7 blocos: manipulação e manipuladores, atividades, suporte operacional, edificação e instalação, preparação do alimento, exposição ao consumo do alimento preparado, documentação e registro. Dos 61 itens avaliados 13 estavam em conformidade, correspondendo à $21 \%$ dos itens do checklist e 39 itens não estavam em conformidade, correspondendo à $64 \%$ do total. Após a implantação do plano de ação houve uma reavaliação para observar as mudanças e melhorias, obtendo-se os seguintes resultados: dos 61 itens avaliados 41 estavam em conformidade ( $67 \%$ do total). Continuaram em desconformidade 19 itens (31\%). Essas irregularidades foram observadas devido às condições físicas que não podem ser modificadas por serem estruturas públicas [17].

Ao comparar os resultados do presente estudo com os demais estudos apresentados acima, observa-se sintonia nos resultados encontrados. Em comum, as instituições apresentam serviços de alimentação despreparados para cumprir os itens de Boas Práticas, gerando risco de surtos de doenças transmitidas por alimentos entre a comunidade acadêmica. Como ponto positivo destacam-se as melhorias observadas em todos os estudos após capacitação de manipuladores, mostrando a importância da qualificação na gestão de pessoas. Esses estudos reforçam a necessidade da implantação das Boas Práticas como ferramenta de qualidade em serviços de alimentação.

\section{CONCLUSÃO}

Os resultados identificaram falta de conhecimentos básicos sobre Boas Práticas nas cantinas do campus do Pici da UFC, localizado em Fortaleza-CE.

Inicialmente foram encontradas cantinas sem estrutura física adequada e ausência de responsáveis técnicos como nutricionistas. O responsável técnico atua garantindo a qualidade no preparo de refeições através da gestão de pessoas, capacitando manipuladores quanto à higiene e segurança das refeições servidas, minimizando, assim, riscos de doenças transmitidas por alimentos.

Os funcionários e administradores nunca foram capacitados a manipular e comercializar alimentos, mas trabalham nesses espaços há pelo menos 2 anos.

Os processos de licitação nos quais os permissionários submetem suas propostas não incluem cláusulas nas quais a alimentação segura seja garantida. Verificou-se também a falta de fiscalizações nesses estabelecimentos. Os critérios adotados na seleção de locatários desses espaços levam em consideração apenas aspectos socioeconômicos, sem garantir a oportunidade de crescimento profissional, ou ainda, de melhoria das condições estruturais e de higiene desses serviços de alimentação.

O desrespeito à legislação de Boas Práticas dos Serviços de Alimentação, vigentes no país, contribui para a perpetuação de produção de refeições sem a garantia de qualidade quanto ao aspecto higiênico sanitário.

Apesar da melhoria na classificação das cantinas, de acordo com o checklist elaborado seguindo 
as RDCs no 216 e no 275 da ANVISA, é preciso ter cautela quanto à qualidade das refeições por elas servidas. Deve-se considerar a ausência de responsáveis técnicos, a inexistência de Manuais de Boas Práticas e de fiscalização desses ambientes.

É importante salientar que a carga horária limitada da capacitação oferecida não permitiu aprofundar o vasto conteúdo de segurança dos alimentos, abrangendo noções de Boas Práticas e as "cinco chaves" para uma alimentação mais segura. Ainda assim, percebe-se um resultado positivo não só quanto à melhoria da classificação dessas unidades de alimentação, mas também pela adesão dos funcionários e administradores à capacitação ofertada, e pela receptividade e interesse em participar do projeto.

Estudos como este alertam a população usuária desses serviços quanto aos riscos do consumo de alimentos manipulados de forma inadequada e podem ser utilizados na elaboração de campanhas dentro da própria universidade para incentivar a qualificação na gestão de pessoas e capacitação de equipes que trabalham com serviços de alimentação, bem como de reformas na estrutura física dos estabelecimentos.

Essas cantinas e trailers continuam ofertando seus serviços a uma grande parcela da comunidade acadêmica, o que demonstra a necessidade de novos estudos que mostrem as razões dessa procura, considerando outras características, tais como, sensoriais, nutricionais e simbólicas, bem como a evolução da qualidade higiênico-sanitária.

Torna-se importante que a universidade desenvolva parcerias com os estabelecimentos que fornecem refeições à comunidade acadêmica, através de projetos que promovam qualidade. A instituição deve investir principalmente na melhoria da estrutura física, estimulando a adesão a programas que promovam a segurança dos alimentos, tais como o Programa Alimento Seguro (PAS), visto que, diante das condições financeiras dos administradores dessas cantinas, torna-se difícil a contratação de serviços de consultoria particulares, ou ainda de certificações.

A qualificação e capacitação de recursos humanos e a fiscalização dos serviços de alimentação oferecidos dentro dos campi da UFC, e de outras universidades brasileiras, deve garantir a segurança dos alimentos e promover a saúde da comunidade acadêmica.

\section{REFERÊNCIAS}

[1] World Health Organization. The role of food safety in health and development. Genebra; 1984.

[2] Instituto Brasileiro de Geografia e Estatística (IBGE). POF 2008/09 mostra desigualdades e transformações no orçamento das famílias brasileiras [Internet]. Brasilia; 2012. [acesso em 20 nov 2012]. Disponível em: http://www.ibge.gov.br/home/presidencia/noticias/noticia _visualiza.php?id_noticia $=1648$ \&id_pagina $=1$

[3] Araujo WMC. Qualidade dos alimentos comercializados no Distrito Federal no período de 1997-2001 [dissertação de mestrado]. Brasilia: Universidade de Brasília; 2002.

[4] Weingold SE, Guzewich J, Fudala JK. Use of Foodborne disease data for HACCP risk assessment. J Food Protect. 1994; 57:820-30.

[5] Nascimento GA, Barbosa JS. BPF - Boas Práticas: uma revisão. Hig Aliment. 2007;21(148):24-30.

[6] Ministério da Saúde. Secretaria de Vigilância em Saúde. Dados epidemiológicos: DTA período de 2000-2011. [Internet]. Brasília; 2012. [acesso em 20 nov 2012]. Disponível em: http://portal.saude.gov.br/portal/arquivos/pdf/dados_dta _periodo_2000_2011_site.pdf

[7] Silva EA Jr. Manual de controle higiênico sanitário em alimentos. 6. ed. atual. São Paulo: Varela; 2005.

[8] Gois JA, et al. Capacitação dos manipuladores de alimentos e qualidade da alimentação servida. Hig Aliment. 2001;15(82):20-2.

[9] Brasil. Agência Nacional de Vigilância Sanitária. Resolução de Diretoria Colegiada no 216. Diário Oficial da União, de 16 de setembro de 2004. Dispõe sobre Regulamento Técnico de Boas Práticas para Serviços de Alimentação. Brasília; 2004.

[10] Brasil. Ministério do Desenvolvimento Social [Internet]. Lei Orgânica de Segurança Alimentar e Nutricional LOSAN, no 11.346, de 15 de setembro de 2006. Brasília; 2012 [acesso em 21 nov 2012]. Disponível em: http://www.mds.gov.br/segurancaalimentar/

[11] Cavalli SB, Salay E. Gestão de pessoas em unidades produtoras de refeições comerciais e a segurança alimentar. Rev Nutr. 2007;20(6):657-67. 
[12] Germano PML, et al. Manipuladores de alimentos: capacitar? É preciso. Regulamentar? Será preciso? Hig aliment. 2002;14(78-79):18-22.

[13] Brasil. Agência Nacional de Vigilância Sanitária. Resolução de Diretoria Colegiada no 275 . Diário Oficial da União, 6 de novembro de 2002. Dispõe sobre o Regulamento Técnico de Procedimentos Operacionais Padronizados aplicados aos Estabelecimentos Produtores/Industrializadores de Alimentos e a Lista de Verificação das Boas Práticas em Estabelecimentos Produtores/Industrializadores de Alimentos. Brasília; 2002.

[14] World Health Organization [Internet]. Cinco Chaves para uma alimentação mais segura; 2012 [acesso em 21 nov 2012]. Disponível em: http://www.who.int/foodsafety/publications/consumer/e n/5keys_Portuguese.pdf.
[15] Cardoso RCV, Sousa EVA, Santos PQ. Unidades de alimentação e nutrição nos campi da Universidade Federal da Bahia: um estudo sob a perspectiva do alimento seguro. Rev Nutr. 2005;18(5):669-80.

[16] Silva SF, Saccol ALF, Mesquita MO. Avaliação das boas práticas em cantina universitária. Disc Scientia. 2007;8(1):151-7.

[17] Centenaro AI, Mendonça SNTG, Lima DP. Implantação das boas práticas para serviços de alimentação na cantina da UTFPR campus Medianeira. In: Anais do XIV Seminário de Iniciação Científica e Tecnológica do Instituto da UTFPR; 2009. Universidade Tecnológica Federal do Paraná - UTFPR. Medianeira: Seminário de Iniciação Científica e Tecnológica da UFTPR; 2009. 


\section{LISTA DE VERIFICAÇÃO DAS CONDIÇÕES HIGIÊNICO-SANITÁRIAS UTILIZADA NA COLETA DE DADOS, BASEADA NAS RDCs № 275/2002 E № 216/2004 DA AGÊNCIA NACIONAL DE VIGILÂNCIA SANITÁRIA (ANVISA)}

\section{DADOS DO ESTABELECIMENTO}

Razão Social:

Nome Fantasia:

CNPJ:

Endereço:

Responsável Legal:

RG:

Endereço:

Responsável Técnico:

RG:

Conselho Regional:

Endereço:

$\begin{array}{lr} & \text { Atividade: } \\ \text { INSC. EST.: } & \text { TEL: }\end{array}$

CPF:

Data de expedição:

TEL:

CPF:

Data de expedição:

№ de registro:

TEL:

1. Ausência de focos de insalubridade (imediações, local e dependências anexas limpas; ausência de objetos em desuso e animais domésticos; ausência de insetos e roedores).

2. Acesso controlado, direto e independente, não comum a outros usos.

3. Edificações e instalações projetadas de forma a possibilitar um fluxo ordenado e sem cruzamento e facilitando a manutenção e limpeza.

4. Separação por meios físicos ou técnicos de áreas para as atividades de preparo das diferentes categorias de alimentos de forma a evitar a contaminação cruzada. 5. PISO

5.1. Possui revestimento liso, impermeável e lavável.

5.2. Em bom estado de conservação, livre de rachaduras, trincas ou outros que possibilitem a contaminação dos alimentos.

5.3. Em bom estado de higienização.

6. PAREDES

6.1. Possuem revestimento liso, impermeável e lavável.

6.2. Em bom estado de conservação; livres de rachaduras, trincas ou outros que possibilitem a contaminação dos alimentos.

6.3. Em bom estado de higienização.

7. TETO

7.1. Possui revestimento liso, impermeável e lavável.

7.2. Em bom estado de conservação; livre de rachaduras, trincas ou outros que possibilitem a contaminação dos alimentos.

7.3. Em bom estado de higienização.

8. PORTAS

8.1. Portas em bom estado de conservação e ajustados ao batente.

8.2. Portas da área de preparação e armazenamento de alimentos são dotadas de fechamento automático.

9. JANELAS

9.1. Janelas em bom estado de conservação; ajustadas ao batente, com vidros íntegros.

9.2. Janelas e outras aberturas externas, incluído o sistema de exaustão são providas de telas milimétricas, para facilitar a limpeza periódica.

10. ILUMINAC̄̃̃

10.1. Iluminação adequada, sem zona com sombra ou contrastes excessivos.

10.2. Luminárias localizadas sobre a área de preparação dos alimentos estão protegidas contra explosão ou queda acidental.

10.3. Instalações elétricas embutidas ou protegidas em tubulações externas, integradas de forma a permitir higienização. 
Continuação

11. VENTILAÇÃO

11.1. Ventilação natural ou artificial adequada (de forma a não permitir gases e fumaça, condensação de vapores, ou surgimento de fungos ou bolores).

11.2. O fluxo de ar não incide diretamente sobre os alimentos.

11.3. Equipamentos de ventilação em bom estado de conservação e limpeza.

11.4. Quando do uso de equipamento para climatização, a empresa possui registro de manutenção dos equipamentos e limpeza e troca dos filtros.

12. Eliminação adequada de águas servidas e esgotadas na rede pública de esgotos. Caixa de gordura em bom estado de conservação e funcionamento, ralo sifonado e tampa giratória.

13. ÁGUA

13.1. Água potável originada de rede pública tratada, poço raso ou profundo tratado.

13.2. Em volume e pressão adequada.

13.3. Caixa d'água tampada e limpa.

14. INSTALAÇÕES SANITÁRIAS

14.1. Instalações sanitárias e vestiários sem comunicação direta com a área de preparação e armazenamento de alimentos ou refeitórios.

14.2. Em bom estado de conservação e organizadas.

14.3. Em bom estado de higienização.

14.4. Portas externas dotadas de fechamento automático.

14.5. São dotadas de lavatórios, com acessórios para higienização das mãos (sabonete líquido antisséptico ou sabonete líquido e produto antisséptico e toalhas de papel não reciclado).

14.6. Possuem lixeiras dotadas de saco plástico e tampa com acionamento por pedal. 15. LAVATÓRIOS EXCLUSIVOS PARA HIGIENIZAÇÃO DAS MÃOS NA ÁREA DE MANIPULAÇÃO DE ALIMENTOS

15.1. Localizados em posição estratégica em relação ao fluxo de preparo dos alimentos e em número suficiente.

15.2. São dotados de lavatórios, com acessórios para higienização das mãos (sabonete líquido, antisséptico ou sabonete líquido e produto antisséptico e toalhas de papel não reciclado).

15.3. Possuem lixeiras dotadas de saco plástico e tampa com acionamento por pedal.

\section{EQUIPAMENTOS}

16. Equipamentos, móveis e utensílios que entram em contato com alimentos são de materiais resistentes à corrosão e a repetidas operações de limpeza e desinfecção. 17. As superfícies dos equipamentos, móveis e utensílios que entram em contato com alimentos são lisas, impermeáveis, laváveis.

18. As superfícies dos equipamentos, móveis e utensílios que entram em contato com os alimentos estão isentas de rugosidades, frestas e outras imperfeições que possam dificultar a higienização e serem fontes de contaminação dos alimentos.

19. Possui registro de manutenção programada e periódica dos equipamentos e utensílios.

20. Possui registro de calibração dos instrumentos e equipamentos de medição.

21. HIGIENIZAÇÃO DAS INSTALAÇÕES, EQUIPAMENTOS, MÓVEIS E UTENSÍLIOS

21.1. Possui registro de limpeza dos equipamentos, móveis e utensílios, quando não realizado rotineiramente.

21.2. Possui registro de limpeza da caixa de gordura.

21.3. Produtos saneantes utilizados são devidamente regularizados pelo Ministério da Saúde.

21.4. Possui local adequado e protegido para o depósito de material de limpeza.

21.5. Os utensílios utilizados na higienização das instalações são distintos daqueles usados para higienização das partes dos equipamentos e utensílios que entram em contato com alimento.

\section{CONTROLE INTEGRADO DE VETORS E PRAGAS}

22. Edificação, instalações, os equipamentos, os móveis e os utensílios livres da presença ou indício da presença de vetores e pragas urbanas.

23. Existem ações e medidas preventivas para impedir a atração, o abrigo, o acesso, e/ou proliferação dos vetores e pragas urbanas. 
Continuação

24. Controle químico realizado por empresa especializada, devidamente registrada no órgão de Vigilância Sanitária competente.

\section{ABASTECIMENTO DE ÁGUA}

25. Quando utilizada solução alternativa de abastecimento de água, a potabilidade deve ser atestada semestralmente mediante laudos laboratoriais.

26. O gelo para utilização em alimentos é fabricado a partir de água potável.

27. O vapor, quando utilizado em contato direto com alimentos ou com superfícies que entrem em contato com alimentos, é produzido a partir de água potável.

28. Registro de limpeza do reservatório de água.

29. Reservatório higienizado em um intervalo máximo de 6 meses.

30. Reservatório livre de rachaduras, vazamentos, infiltrações e descascamentos.

\section{MANEJO DE RESÍDUOS}

31. Recipientes identificados e íntegros, de fácil higienização e transporte, em número e capacidade suficientes para conter os resíduos.

32. Recipientes dotados de tampa acionadas sem contato manual.

33. Resíduos são coletados frequentemente, evitando acúmulos.

34. São estocados em local fechado e isolado da área de preparação e armazenamento de alimentos.

\begin{tabular}{|c|c|c|c|}
\hline MANIPULADORES & $\mathrm{S}$ & $\mathrm{N}$ & NA \\
\hline $\begin{array}{l}\text { 35. Controle de saúde dos funcionários devidamente registrado e realizado de acordo } \\
\text { com a legislação específica. }\end{array}$ & & & \\
\hline $\begin{array}{l}\text { 36. Ausência de lesões e ou sintomas de enfermidades que possam comprometer a } \\
\text { qualidade higiênico-sanitária dos alimentos ou, quando existir, que estes estejam } \\
\text { afastados das atividades de preparação dos alimentos enquanto persistirem essas } \\
\text { condições de saúde. }\end{array}$ & & & \\
\hline $\begin{array}{l}\text { 37. Boa apresentação, asseio pessoal, usando uniforme de trabalho completo de cor } \\
\text { clara, em bom estado e limpo. }\end{array}$ & & & \\
\hline $\begin{array}{l}\text { 38. Lavagem cuidadosa das mãos antes e após manipular os alimentos, após qualquer } \\
\text { interrupção do serviço e depois de usar os sanitários e sempre que se fizer necessário. }\end{array}$ & & & \\
\hline $\begin{array}{l}\text { 39. Possui cartazes de orientação aos manipuladores sobre a correta lavagem e } \\
\text { antissepsia das mãos e demais hábitos de higiene, afixados em locais de fácil } \\
\text { visualização, inclusive nas instalações sanitárias e lavatórios. }\end{array}$ & & & \\
\hline $\begin{array}{l}\text { 40. Não espirrar e tossir sobre os alimentos, não fumar, falar demasiadamente, cantar } \\
\text { e assobiar enquanto manipulam alimentos, não manipular dinheiro, ou outros atos } \\
\text { físicos que possam contaminar alimentos. }\end{array}$ & & & \\
\hline $\begin{array}{l}\text { 41. Cabelos presos e protegidos por redes, toucas ou outro acessório apropriado para } \\
\text { este fim, sem barba, unhas cortadas e sem esmalte ou base, sem adornos e sem } \\
\text { maquiagem. }\end{array}$ & & & \\
\hline $\begin{array}{l}\text { 42. Capacitação/treinamentos periódicos para os manipuladores, em higiene pessoal, } \\
\text { em manipulação higiênica dos alimentos e em doenças transmitidas por alimentos, } \\
\text { devidamente registrados e documentados. }\end{array}$ & & & \\
\hline $\begin{array}{l}\text { 43. Visitantes cumprem os requisitos de higiene e de saúde estabelecidos para os } \\
\text { manipuladores. }\end{array}$ & & & \\
\hline MATÉRIAS PRIMAS, INGREDIENTES E EMBALAGENS & $\mathrm{S}$ & $\mathrm{N}$ & NA \\
\hline $\begin{array}{l}\text { 44. Possui critérios para avaliação e seleção dos fornecedores de matérias-primas, } \\
\text { ingredientes e embalagens. }\end{array}$ & & & \\
\hline $\begin{array}{l}\text { 45. Recepção das matérias-primas, ingredientes e embalagens são realizadas em área } \\
\text { protegida e limpa. }\end{array}$ & & & \\
\hline $\begin{array}{l}\text { 46. Registro de inspeção das matérias-primas e ingredientes durante a operação de } \\
\text { recepção quanto à integridade das embalagens, temperatura dos produtos que } \\
\text { necessitam de conservação especial. }\end{array}$ & & & \\
\hline $\begin{array}{l}\text { 47. As matérias-primas, ingredientes ou embalagens reprovadas na inspeção realizada } \\
\text { na recepção são imediatamente devolvidas ao fornecedor, ou na impossibilidade são } \\
\text { devidamente identificadas e armazenadas separadamente. }\end{array}$ & & & \\
\hline $\begin{array}{l}\text { 48. Matérias-primas, ingredientes e embalagens são armazenados em local limpo e } \\
\text { organizado de forma a garantir proteção contra contaminação. }\end{array}$ & & & \\
\hline $\begin{array}{l}\text { 49. As matérias-primas e ingredientes obedecem para sua utilização o prazo de } \\
\text { validade. }\end{array}$ & & & \\
\hline
\end{tabular}

Continua 
Continuação

50. As matérias-primas, ingredientes e embalagens são armazenadas sobre palletes, estrados ou prateleiras com altura mínima de $30 \mathrm{~cm}$ do piso e no mínimo $40 \mathrm{~cm}$ afastados das paredes.

\section{PREPARAÇÃO DO ALIMENTO}

51. Durante a preparação dos alimentos são adotados medidas a fim de minimizar o risco de contaminação cruzada, evitando contato direto ou indireto entre alimentos crus, semipreparados e prontos para consumo.

52. Os funcionários que manipulam alimentos crus realizam a lavagem e antissepsia das mãos antes de manusear alimentos preparados.

53. As matérias-primas e ingredientes caracterizados como produtos perecíveis são expostos à temperatura ambiente somente pelo tempo mínimo necessário para a preparação do alimento.

54. As matérias-primas e ingredientes que não são utilizados em sua totalidade são adequadamente acondicionados e identificados com no mínimo, as seguintes informações: designação do produto, data de fracionamento e prazo de validade após a abertura ou retirada da embalagem original.

55. É avaliada a eficácia do tratamento térmico através de verificação da temperatura e do tempo utilizado ou, quando aplicável, pela mudança na textura e cor na parte central dos alimentos.

56. O óleo e gordura utilizados para fritura apresentam boas condições de forma a não se constituírem fontes de contaminações químicas.

57. O óleo e gordura utilizados são substituídos quando estão com aroma e sabor alterados e formação intensa de espuma e fumaça.

58. Os alimentos congelados sofrem descongelamento antes de serem submetidos ao tratamento térmico, excetuando-se os casos em que o fabricante recomenda o tratamento térmico do alimento congelado.

59. O descongelamento dos alimentos é efetuado em condições de refrigeração à temperatura inferior a $5^{\circ} \mathrm{C}$ ou em forno micro-ondas quando o alimento for submetido à cocção.

60. Os alimentos descongelados não são recongelados, sendo a parte não utilizada mantida sob-refrigeração à temperatura inferior a $5^{\circ} \mathrm{C}$.

61. Os alimentos submetidos a cocção e prontos para consumo são mantidos em temperatura superiores a $60^{\circ} \mathrm{C}$ por, no máximo, 6 horas.

62. Os alimentos submetidos à cocção, quando necessário, sofrem refrigeração, diminuindo sua temperatura de $60^{\circ} \mathrm{C}$ para $10^{\circ} \mathrm{C} \mathrm{em}$, no máximo, 2 horas e, em seguida, sendo armazenados em temperatura de refrigeração inferior a $5^{\circ} \mathrm{C}$ ou congelados em temperatura inferior a $-18^{\circ} \mathrm{C}$.

63. Os alimentos preparados e conservados a temperatura inferior a $4^{\circ} \mathrm{C}$ são utilizados num prazo máximo de 5 dias.

64. Os alimentos preparados e conservados sob-refrigeração ou congelados são identificados com, no mínimo, a sua designação, data de preparo e prazo de validade.

65. A temperatura dos equipamentos de frios (geladeira, congeladores etc.) são regularmente monitoradas e registradas em mapa de controle de temperatura. 66. Os alimentos consumidos crus são submetidos a processo de higienização com produtos devidamente registrados no órgão competente do Ministério da Saúde.

\section{ARMAZENAMENTO E TRANSPORTE DO ALIMENTO} PROCESSADO

67. Os alimentos preparados e mantidos na área de armazenamento ou aguardando o transporte estão protegidos contra contaminação e identificados com, no mínimo, a designação do produto, data do preparo e prazo de validade.

68. A temperatura do armazenamento e a distribuição do alimento preparado obedecem as condições de tempo e temperatura que garantam a sua qualidade higiênico-sanitária.

69. Os meios de transporte do alimento preparado são devidamente higienizados e dotados de cobertura para proteção da carga e são de uso exclusivo para alimentos. EXPOSIÇÃO AO CONSUMO DO ALIMENTO PREPARADO

70. A área de exposição do alimento preparado e de consumação ou refeitório são mantidos organizados e em condições higiênico-sanitárias adequadas. 
Continuação

71. Os manipuladores adotam procedimentos de antissepsia das mãos e usam utensílios ou luvas descartáveis.

72. Os equipamentos de exposição do alimento preparado dispõem de barreiras de proteção que previnam a contaminação do alimento pela proximidade ou ação do consumidor ou outras fontes.

73. Os utensílios como pratos, copos e talheres são descartáveis, ou quando não são descartáveis, são devidamente higienizados e armazenados em local protegido.

74. A área reservada para as atividades de recebimento de dinheiro, cartões e outros tipos de pagamento de despesas é reservada e os funcionários responsáveis por esta atividade não manipulam alimentos.

DOCUMENTAÇÃO E REGISTRO

75. O estabelecimento possui Manual de Boas Práticas e procedimentos operacionais padronizados e estão disponíveis para funcionários e para as autoridades sanitárias.

76. Os procedimentos operacionais padronizados (POPs) contêm as instruções sequenciais das operações e a frequência de execução, especificando o nome, o cargo e ou a função dos responsáveis pela atividade. São aprovados datados e assinados pelo responsável pelo estabelecimento.

77. Os registros são mantidos por período mínimo de 30 dias contados a partir do preparo do alimento.

78. Possui POP descrito e implementado para higienização de instalações, equipamentos e móveis.

79. Possui POP descrito e implementado para controle integrado de vetores e pragas urbanas.

80. Possui POP descrito e implementado para higienização do reservatório de água.

81. Possui POP descrito e implementado para higiene e saúde dos manipuladores.

82. Responsáveis pelas atividades e manipuladores de alimentos possuem comprovadamente capacitação abordando, no mínimo, os seguintes temas: contaminantes alimentares, doenças transmitidas por alimentos, manipulação higiênica dos alimentos e boas práticas.

OBSERVAÇÕES:

DATA: HORA:

\begin{tabular}{|l|l|l|}
\hline & & \\
\hline & & \\
\hline & & \\
\hline
\end{tabular}

ASSINATURA:

$\mathrm{S}=\operatorname{sim} ; \mathrm{N}=$ não; $\mathrm{NA}=$ não se aplica.

AVALIAÇÃO DOS ESTABELECIMENTOS: Com o resultado da somatória dos (S) faz-se a porcentagem simples retirando os itens que não se aplicam

(NA) e classifica o estabelecimento dentro dos seguintes grupos:

Quando o estabelecimento atender de $0 \%$ a $50 \%$ dos itens do checklist, deve ser classificado no Grupo3.

Quando o estabelecimento atender de $51 \%$ a $75 \%$ dos itens do checklist, deve ser classificado no Grupo 2.

Quando o estabelecimento atender de $76 \%$ a $100 \%$ dos itens do checklist, deve ser classificado no Grupo 1 . 